Images In...

\title{
Gallbladder visualisation after intravenous urography
}

\author{
Hsueh-Ling Kao, ${ }^{1}$ Ming-Chieh Tsai, ${ }^{2,3}$ Shao-Kuan Chen, ${ }^{3,4}$ Yen-Chieh Wang ${ }^{3,4}$
}

${ }^{1}$ Department of Nursing, Sijhih Cathay General Hospital, Taipei, Taiwan

${ }^{2}$ Department of Internal Medicine, Sijhih Cathay General Hospital, Taipei, Taiwan

${ }^{3}$ School of Medicine, College of Medicine, Fu Jen Catholic University, Taipei, Taiwan

${ }^{4}$ Department of Urology, Sijhih Cathay General Hospital, Taipei, Taiwan

Correspondence to Yen-Chieh Wang, litiger.wang@gmail.com

\section{DESCRIPTION}

A 42-year-old man presented to the Emergency Department with a sudden onset of right renal colic. Physical examination showed knocking tenderness on the rightsided costovertebral angle. Laboratory evaluation was unremarkable except haematuria on urinalysis. Abdominal radiography of the kidneys, ureters, and bladder (KUB) was negative. Intravenous urography, using $50 \mathrm{ml}$ of $76 \%$ amidotrizoate as a bolus, demonstrated right-sided obstructive uropathy (figure 1). Immediate ureteroscopy revealed a calculus impacted in the lower third of the right ureter. Lithotripsy with a double J stenting was performed. A postoperative KUB scan showed a tobacco-pipe-shaped accumulation of contrast medium in the right upper quadrant (figure 2), which was initially misidentified as an extravasation of contrast medium into the bowel. Nonenhanced CT revealed contrast medium totally collected within the gallbladder without extravasation (figure 3). The patient recovered uneventfully and a KUB scan showed complete resolution of previously enhanced gallbladder on postoperative day 2. The patient was free of obstructive uropathy or gallbladder illness during the 12-month followup period.

In the face of acute unilateral obstructive uropathy ${ }^{1}$ or chronic renal failure, ${ }^{2}$ the gallbladder is able to excrete iodinated contrast media, referred to as 'vicarious excretion', resulting in enhancement of the gallbladder on KUB scan or CT 4.5-95 h after intravenous injection of iodinated contrast media. ${ }^{1}$ Doctors should take a careful look at the opacification on right upper abdomen during abdominal radiographic or tomographic evaluation in cases with recent injection of contrast media and be aware that vicarious excretion of contrast media should be distinguished from extravasation or leakage from the urinary tract.
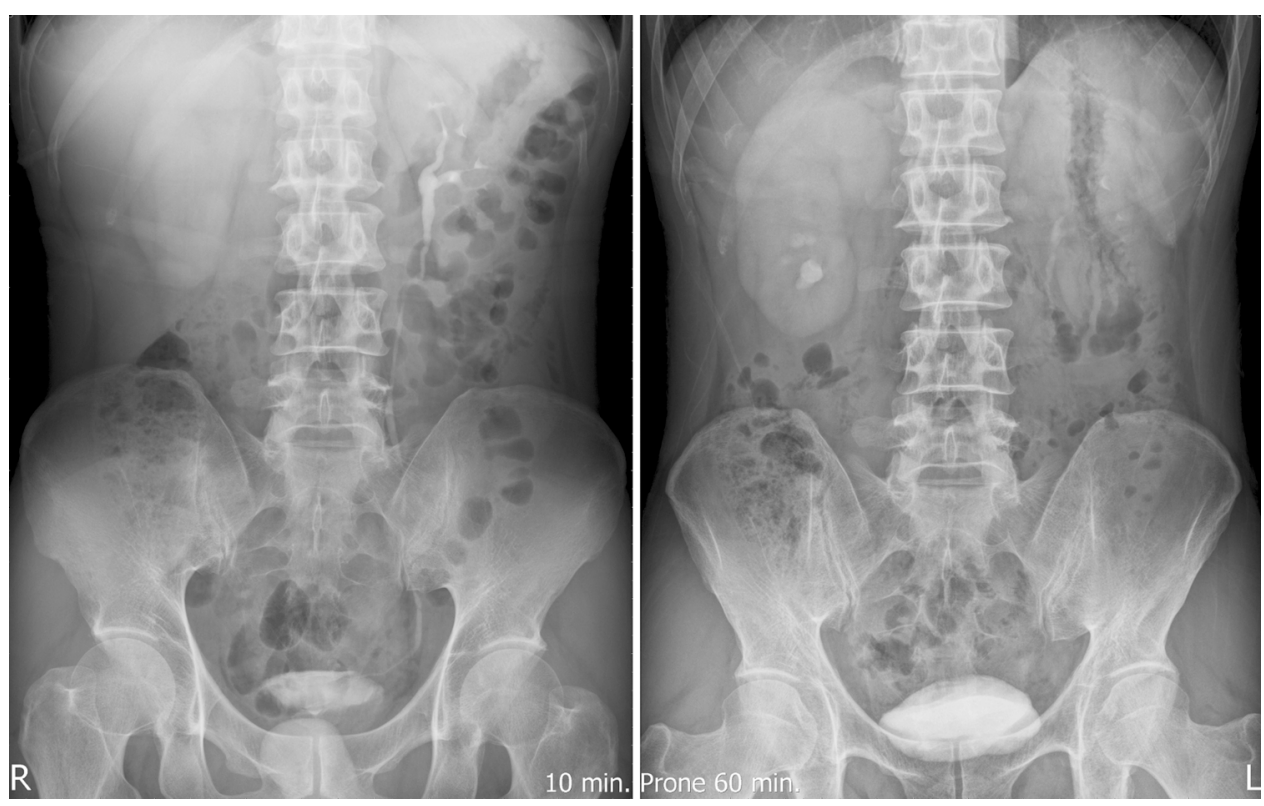

Figure 1 Intravenous urography showing markedly delayed visualisation of right collecting system, compatible with right-sided obstructive uropathy. 


\section{BMJ Case Reports}

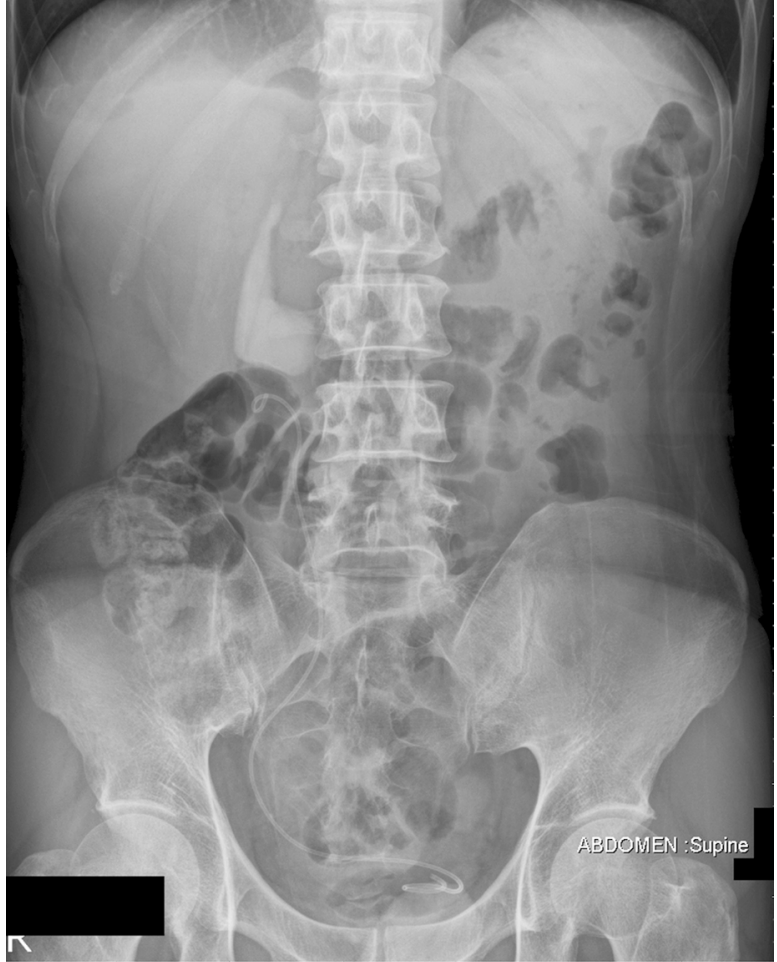

Figure 2 Postoperative abdominal radiography $20 \mathrm{~h}$ after intravenous injection of contrast medium showing tobacco-pipeshaped accumulation of contrast medium in the right upper quadrant, consistent with enhancement of the gallbladder, and a double $\mathrm{J}$ stenting in the right ureter.

Competing interests None.

Patient consent Obtained.

\section{REFERENCES}

1. Dyer RB, Gilpin JW, Zagoria RJ, et al. Vicarious contrast material excretion in patients with acute unilateral ureteral obstruction. Radiology

1990;177:739-42.

2. Lautin EM, Friedman AC. Vicarious excretion of contrast media. JAMA 1982;247:1608-10.
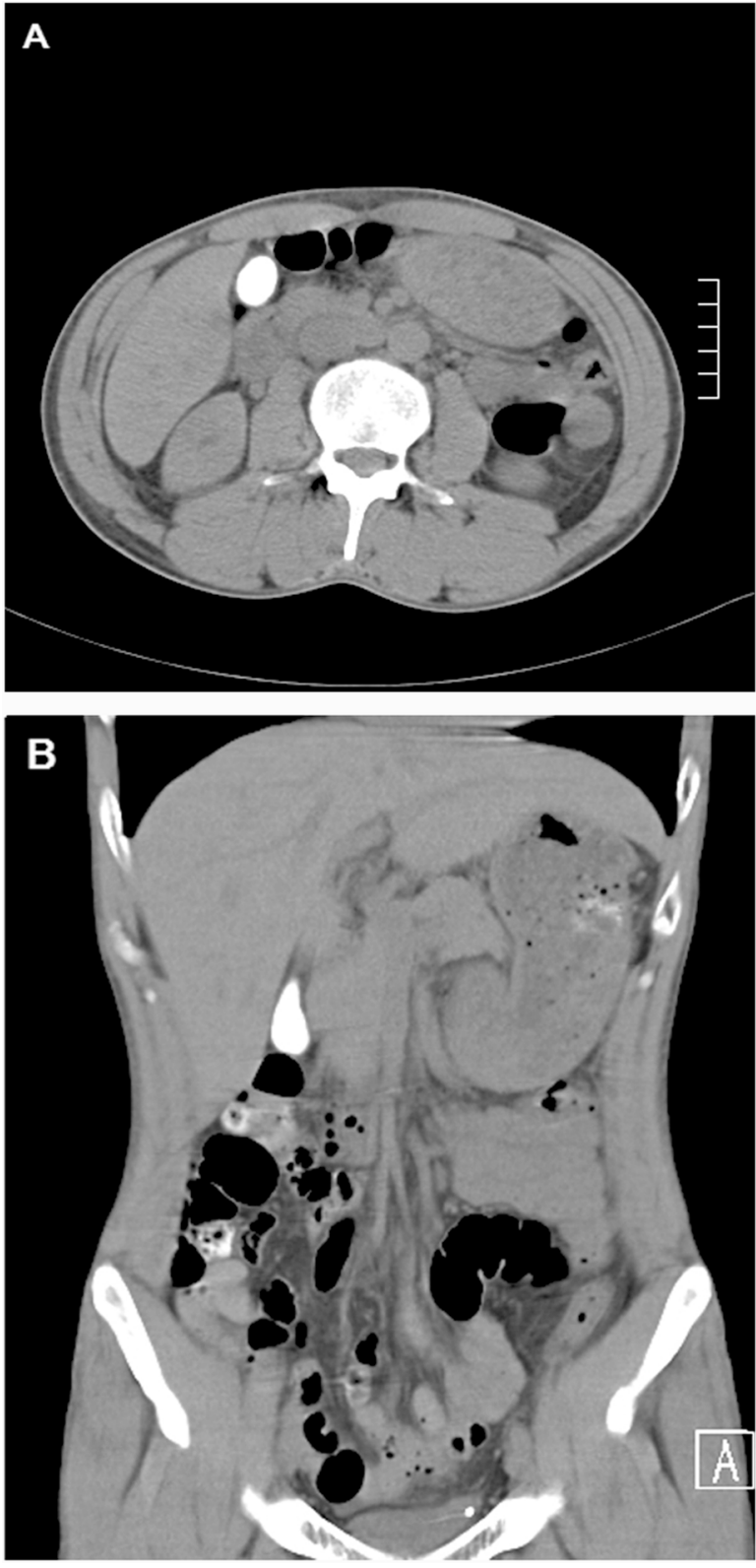

Figure 3 Non-enhanced CT (axial view (A) and coronal view (B)) showing high-density contrast medium collection within the distended gallbladder without extravasation. 


\section{BMJ Case Reports}

This pdf has been created automatically from the final edited text and images.

Copyright 2010 BMJ Publishing Group. All rights reserved. For permission to reuse any of this content visit http://group.bmj.com/group/rights-licensing/permissions.

BMJ Case Report Fellows may re-use this article for personal use and teaching without any further permission.

Please cite this article as follows (you will need to access the article online to obtain the date of publication).

Hsueh-Ling K, Ming-Chieh T, Shao-Kuan C, Yen-Chieh W. Gallbladder visualisation after intravenous urography. BMJ Case Reports 2010; 10.1136/bcr.03.2010.2860, date of publication

Become a Fellow of BMJ Case Reports today and you can:

- Submit as many cases as you like

- Enjoy fast sympathetic peer review and rapid publication of accepted articles

- Access all the published articles

- Re-use any of the published material for personal use and teaching without further permission

For information on Institutional Fellowships contact consortiasales@bmjgroup.com

Visit casereports.bmj.com for more articles like this and to become a Fellow 